\title{
Gonadotropin-releasing hormone and adipokinetic hormone signaling systems share a common evolutionary origin
}

\author{
Marleen Lindemans ${ }^{\dagger}$, Tom Janssen ${ }^{\dagger}$, Isabel Beets, Liesbet Temmerman, Ellen Meelkop and Liliane Schoofs*
}

Functional Genomics and Proteomics Research Unit, Katholieke Universiteit Leuven, Leuven, Belgium

\section{Edited by:}

Billy K. C. Chow, University of Hong

Kong, China

Reviewed by:

Hervé Tostivint, Natural History

Museum, France

Alice Wong, The University of Hong

Kong, Hong Kong

${ }^{*}$ Correspondence:

Liliane Schoofs, Functional Genomics and Proteomics Research Unit,

Zoological Institute, Katholieke

Universiteit Leuven, Naamsestraat

59, B-3000 Leuven, Belgium.

e-mail: liliane.schoofs@bio.

kuleuven.be

${ }^{\dagger}$ Marleen Lindemans and Tom

Janssen have contributed equally to this work.
Gonadotropin-releasing hormone $(\mathrm{GnRH})$ is a critical and central hormone that regulates vertebrate reproduction. The high conservation of $\mathrm{GnRH}$ signaling within the chordates (deuterostomians) raises the important question as to whether its appearance might date back prior to the divergence of protostomian and deuterostomian lineages, about 700 million years ago. This leads to several important questions regarding the evolution of the $\mathrm{GnRH}$ family. Has $\mathrm{GnRH}$ been retained in most protostomian lineages? And was regulation of reproduction already a function of ancestral $\mathrm{GnRH}$ ? The first question can undoubtedly be answered affirmatively since several GnRH-like sequences have been found in wide variety of protostomian and deuterostomian phyla. However, based on their different primary functions in different phyla - which implies a less unanimous answer on the second question - consistency in the nomenclature of this peptide family has been lost. A comparative and phylogenetic approach shows that the ecdysozoan adipokinetic hormones (AKHs), lophotrochozoan GnRHs and chordate GnRHs are structurally related and suggests that they all originate from a common ancestor. This review supports the view that the $\mathrm{AKH}-\mathrm{GnRH}$ signaling system probably arose very early in metazoan evolution, prior to the divergence of protostomians and deuterostomians.

Keywords: gonadotropin-releasing hormone, adipokinetic hormone, neuropeptide, G protein-coupled receptor, reproduction, metabolism, evolution

\section{INTRODUCTION}

Gonadotropin-releasing hormone (GnRH) is well known for its control of vertebrate reproduction, via the pituitary, where it regulates the synthesis and release of the gonadotropins luteinizing hormone (LH) and follicle-stimulating hormone (FSH; Kah et al., 2007). Its mammalian structure was originally thought to be unique until it became apparent that diverse forms of this peptide hormone exist in vertebrates. At present, the chordate GnRH family consists of 25 members: 16 variants have been found in vertebrates (Morgan and Millar, 2004; Guilgur et al., 2006; Kavanaugh et al., 2008; Kim et al., 2011), and nine in tunicates (Adams et al., 2003). Some vertebrates, like chickens, express two and some teleost fish even three different forms of GnRH (Millar, 2005), which is the result of gene duplications, diversifications, and losses (Stewart et al., 2009). Recent studies demonstrate by genome synteny analyses that the GnRH family most likely comprises three paralogous genes (GnRH1, GnRH2, and GnRH3) resulting from a genome/gene duplication event affecting the common ancestor of lamprey and gnathostome isoforms. An additional group of GnRH4 isoforms (consisting of lamprey GnRH-I and GnRH-III) is present only in lampreys without any counterpart in the gnathostome lineage (Kim et al., 2011; Tostivint, 2011). All these chordate $\mathrm{GnRH}$ s signal through $\mathrm{G}$ protein-coupled receptors (GPCRs), which consist of seven-transmembrane (7TM) helices and signal through $\mathrm{G} \alpha \mathrm{q}$ with $\mathrm{Ca} 2+$ as second messenger. $\mathrm{GnRH}$ receptors have been reported in the cephalochordate Amphioxus, in tunicates, agnathans, and in various vertebrates (Kah et al., 2007; Tello and Sherwood, 2009).

The existence of a putative functional equivalent of this peptide hormone and its receptor in protostomian invertebrates has been a matter of debate. Because the basic concepts of sexual reproduction are similar in most animal phyla, it is tempting to hypothesize that the regulation of reproduction must have been highly conserved and may date back to the common ancestor of protostomians and deuterostomians. The first reported protostomian GnRH sequence has been reported in the mollusk Octopus vulgaris (Iwakoshi et al., 2002). Until recently, GnRH-related peptides were only established in two protostomian phyla belonging to the Lophotrochozoa: the mollusks (Sepia officinalis, Di Cristo et al., 2008b; Aplysia californica, Zhang et al., 2000; and Lottia gigantea, Tsai and Zhang, 2008) and annelids (Capitella teleta, Tsai and Zhang, 2008; and Helobdella robusta, Roch et al., 2011).

\section{IS GnRH ALSO PRESENT IN ECDYSOZOANS?}

Recently, Tsai and Zhang (2008) reported that chordate and protostomian GnRHs likely share a common ancestor. They proposed that $\mathrm{GnRH}$ has been preserved in lophotrochozoans (annelids and mollusks), but lost in the ecdysozoan lineage (nematodes and arthropods; Tsai and Zhang, 2008). According to their view, GnRHR-like receptors have been retained in Ecdysozoa but they 
have recruited other ligands to bind. The ligand of the $\mathrm{GnRH}$ receptor of the insects Drosophila melanogaster and Bombyx mori has been identified as adipokinetic hormone (AKH; Staubli et al., 2002). AKH is an insect neurohormone that is synthesized in the corpora cardiaca (CC; O'Shea and Rayne, 1992), a neurohemal organ which is considered as the functional equivalent of the vertebrate pituitary gland. $\mathrm{AKH}$ is involved in mobilizing energycontaining substances such as sugar and lipids from the fat body during flight and locomotion (Gade, 2004).

A breakthrough into the common evolution of $\mathrm{AKH}$ and GnRH came with the demonstration of an AKH-GnRH-like neuropeptide in the nematode Caenorhabditis elegans (Ce-AKH$\mathrm{GnRH}$ ), which is reminiscent of both insect AKHs and of GnRHs from tunicates and higher vertebrates (Lindemans et al., 2009). Although it has a small size and, at first sight, simple anatomy containing only 302 neurons, this small soil nematode has already repeatedly proven its value in neurobiological and endocrinological research (Janssen et al., 2010). The C. elegans AKH-GnRH neuropeptide has been found by a bioinformatics approach based on the Prosite pattern that characterizes the AKH family. The amino acid sequence of the novel $C$. elegans neuropeptide (pQMTFTDQWT) is more similar to AKH than to GnRH (Figure 1). CeAKH-GnRH activates in a dose-dependent way a C. elegans GPCR (Lindemans et al., 2009) that is homologous to the human GnRH receptor and has been designated as the C. elegans $\mathrm{GnRH}$ receptor (Ce-GnRHR; Vadakkadath et al., 2006). This receptor signals through $\mathrm{G} \alpha \mathrm{q}$, analogous to most $\mathrm{AKH}$ and $\mathrm{GnRH}$ receptors. EST libraries available on the web (http://www.nematode.net/BLAST/) and a NCBI BLAST search revealed orthologous AKH-GnRHlike precursor sequences in parasitic nematodes (Figure 1). All these nematode AKH-GnRH sequences activate the Ce-GnRHR in a dose-dependent way (Lindemans et al., 2009), demonstrating that the AKH-GnRH neuropeptide is widespread throughout the phylum of nematodes.

\section{GnRH AT THE CHORDATE ROOT}

Non-vertebrate chordates, like Amphioxus, provide very valuable information about GnRH signaling at the basis of the chordate lineage. The Amphioxus genome encodes, as a result of gene duplications, four GnRH receptors. GnRHR1 and 2 have a higher degree of conservation with vertebrate orthologs and are activated by vertebrate GnRHs, whereas GnRHR3 and 4 rather cluster with protostomian GnRH receptors (Roch et al., 2011). An additional strong argument for the common origin of $\mathrm{AKH}$ and GnRH came with the demonstration of insect AKH and mollusk GnRH activating the Amphioxus GnRHR3 in a dose-dependent way, even with a higher potency than two chordate GnRH sequences (GnRHR4 was non-responsive; Tello and Sherwood, 2009). This indicates that Amphioxus receptors might provide an explanation for the evolutionary distinct protostomian and deuterostomian $\mathrm{GnRH}$ signaling systems.

\section{THE AKH-GnRH SUPERFAMILY}

Chordate GnRH is a short, highly conserved decapeptide hormone with four identical residues (positions 1, 4, 9, and 10) of the 10 (Gorbman and Sower, 2003; Kah et al., 2007). Lophotrochozoan GnRHs count usually 11 or 12 residues and ecdysozoan AKHs 9 or
10 (Figure 1). All known AKH and GnRH peptides start with an $\mathrm{N}$-terminal pyroglutamate residue and all processed peptides are amidated except the nematode ones. A plausible hypothesis is that a non-amidated $\mathrm{AKH}$ is the most ancient form and that amidation arose later in evolution. However, it is also possible that amidation might have been lost later in evolution. Non-amidated AKH is also found in the painted lady butterfly Vanessa cardui (Kollisch et al., 2000) and in the fall armyworm Spodoptera frugiperda (AbdelLatief and Hoffmann, 2007) both belonging to the Lepidoptera. The $\mathrm{F}(\mathrm{S} / \mathrm{T})$ signature in the middle of the AKH-GnRH peptide sequences is common to all protostomian peptides and, remarkably, also in the echinoderm sea urchin (deuterostomian) Strongylocentrotus purpuratus, which resembles more the protostomian GnRHs from annelids and mollusks than the chordate GnRHs that are characterized by a middle WS motif. Further on in the peptide sequence, a tryptophan residue has been well conserved in the protostomian lineage, in the more ancient deuterostomians and also in the ancient chicken GnRH2 (QHWSHGWYPG-NH 2 ), but has been lost in the amphibians. Moreover, there are striking overall structural similarities between $\mathrm{AKH}$ and $\mathrm{GnRH}$ precursors (Lindemans et al., 2009): the GnRH or AKH peptide sequence is located immediately after the signal peptide and is flanked at the C-terminus by a basic cleavage site. The C-terminal flanking peptides contain two cysteine residues in all protostomian $\mathrm{AKH}-$ GnRH prepropeptides, except for locust AKH-I and II. Associated peptides in the chordate precursors have one or no Cys residue. All these findings provide strong evidence for a common origin of AKHs and GnRHs (Figure 2). The nematode and arthropod (ecdysozoans) AKH-GnRH-like-precursor seems to have diverged substantially from chordate GnRH during the course of evolution. This finding in combination with the rapid divergence of short neuropeptide sequences hampers the identification of homologous genes in the different phyla by comparative genomic tools (e.g., BLAST).

Another group of peptides that are structurally related to AKHs are the corazonins. The first member of this class of peptides present in insects and crustaceans - was identified from the CC of the cockroach Periplaneta americana (Veenstra, 1989). Corazonins have very varying functions in different species, but no generalized role. In cockroaches, they have cardiostimulatory effects (Veenstra, 1989), while in locusts they cause increased pigmentation (Hua et al., 2000) and in silk worms a decreased silk production (Tanaka et al., 2002).

Very recent evidence for the close relationship between both insect neuropeptide groups came from the discovery of an $\mathrm{AKH} /$ corazonin-related peptide (ACP; pQVTFSRDWNA-NH $\mathrm{N}_{2}$ ) in the mosquito Anopheles gambiae (Ag-AKH2 in Figure 1; Hansen et al., 2010). Apart from two carboxyterminal amino acids, this Anopheles sequence is completely identical to hypertrehalosaemic hormone of Locusta migratoria (Lm-HrTH), another AKH-like neuropeptide (pQVTFSRDWSP-NH $\mathrm{N}_{2}$; Siegert, 1999). In contrast to Lm-AKH-I, II, and III, which are present in the glandular lobe of the CC, $\mathrm{Lm}-\mathrm{HrTH}$ is present in the storage lobe of the $\mathrm{CC}$, indicating that this neuropeptide is synthesized in the brain. For this reason and also since there is $36-59 \%$ sequence identity between Lm-HrTH and the three "classic" AKHs, but 78\% identity with Drosophila AKH, it has been suggested before that 


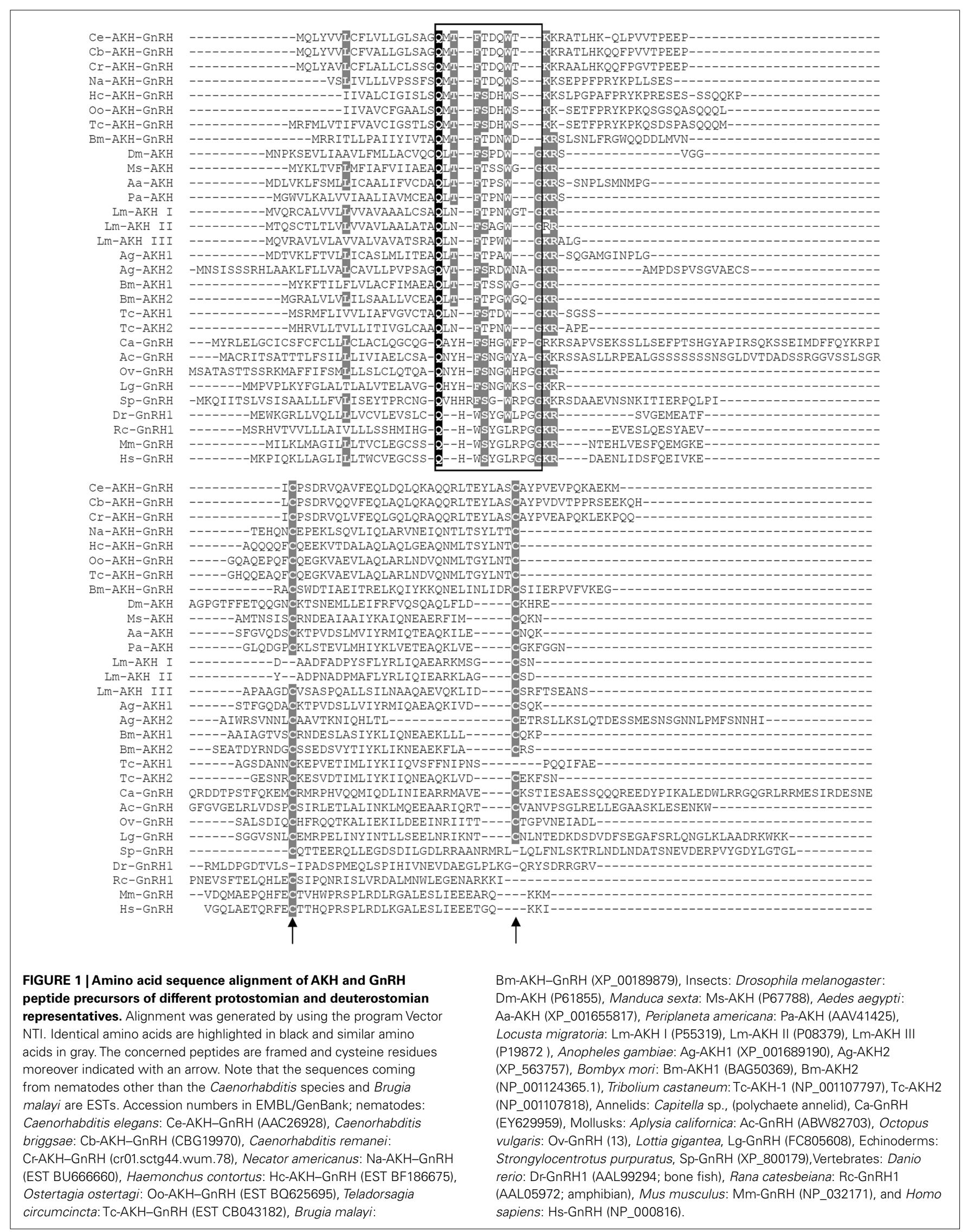




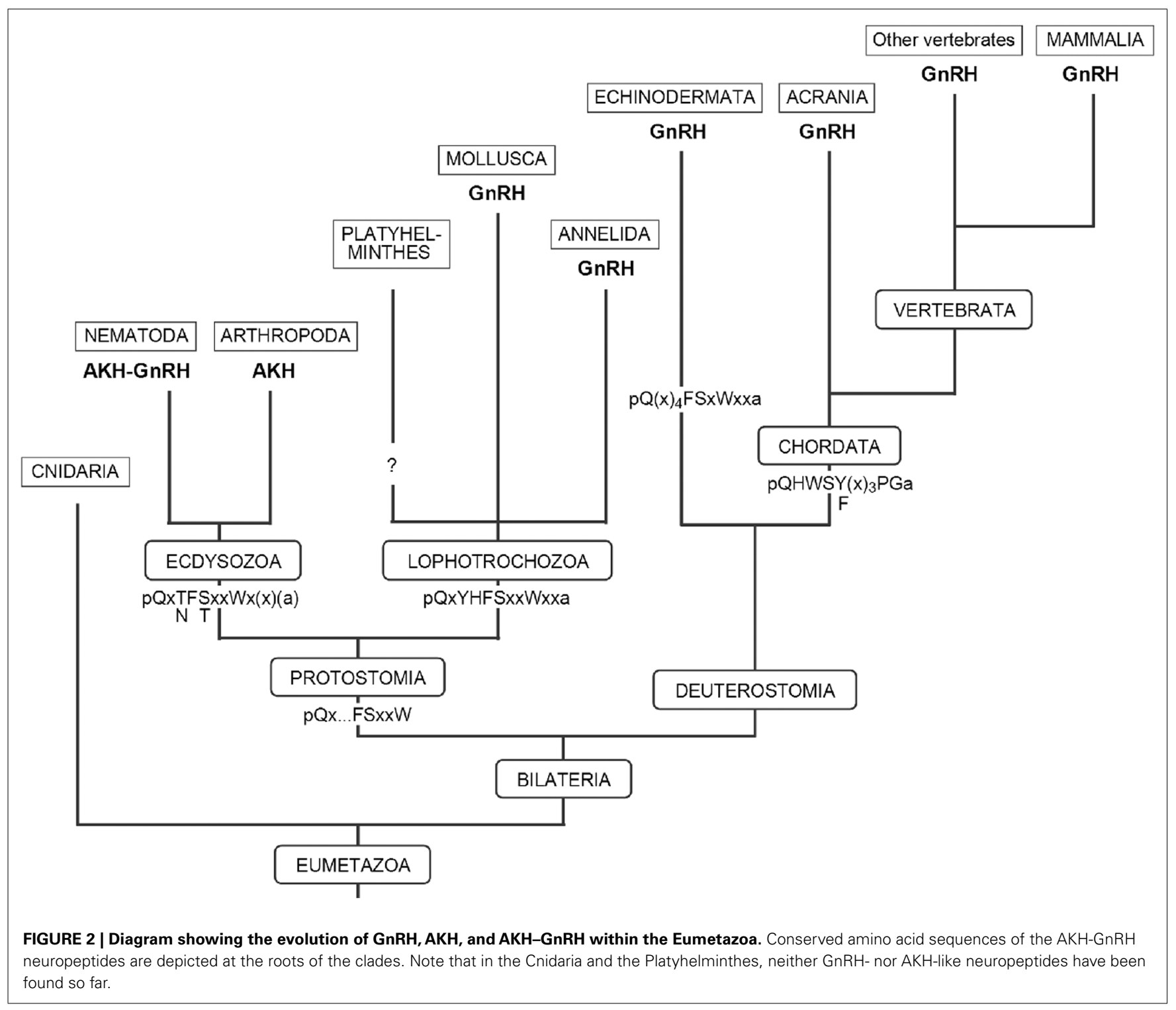

hypertrehalosaemic hormone might be the most ancient $\mathrm{AKH}$ molecule (Siegert, 1999). So far, the precursor sequence of LmHrTH is unknown. However, similar hypertrehalosemic peptides and their precursor genes have been found in the genome of other insects, including dipterans (A. gambiae (Kaufmann and Brown, 2006, 2008; Hansen et al., 2010), lepidopterans (B. mori; Zhu et al., 2009), and coleopterans (Tribolium castanea; Li et al., 2008; Figure 1).

\section{ARE PROTOSTOMIAN GnRHs INVOLVED IN REPRODUCTION?}

Based on its expression pattern in the brain and ovary, it has been proposed that mollusk GnRH plays a role in reproduction (Di Cristo et al., 2008a,b). A GnRH receptor has been reported in the mollusks O. vulgaris (Kanda et al., 2006) and Crassostrea gigas, where qRT-PCR showed a specific expression of $C g$-GnRHR in both male and female gonads during the reproductive cycle (Rodet et al., 2005), demonstrating for the first time the plausible involvement of a GnRH receptor orthologue in the control of reproduction in a protostomian invertebrate. Ecdysozoan $\mathrm{AKH}-$ GnRH involvement in reproduction was for the first time provided by RNAi experiments of the AKH-GnRH precursor and the GnRH receptor in C. elegans. It is clear that Ce-GnRHR and Ce-AKHGnRH affect the same pathway, as their knock-downs yielded the same phenotype: a delay in timing of the egg-laying process as well as a decrease in the total amount of progeny (Lindemans et al., 2009).

Insect $\mathrm{AKH}$, especially involved in energy mobilizing during flight and locomotion, is so far not linked with a role related to reproduction. AKH deficient fruit flies seem to display normal reproductive capabilities, but, to our knowledge, an investigation toward delayed egg-laying has not been performed yet. It is interesting to note that in the fall armyworm $S$. frugiperda AKH mRNAs occur in ovaries, midgut, fat body, accessory glands, and muscle tissues, suggesting that $a k h$ genes may play a role in the regulation of oocyte maturation (Abdel-Latief and Hoffmann, 2007). Also in A. gambiae females, $\mathrm{AKH}$ receptor transcripts are abundant in the 
head, thorax, dorsal, and ventral abdomen walls to which most of the fat body is attached and in ovaries as well (Kaufmann and Brown, 2006). And in locusts, the ancient Lm-HrTH has no biological activity usually associated with the typical AKHs (Siegert, 1999). Its biological role remains to be established, and it would be interesting to determine if it is involved in reproduction.

\section{CONCLUSION}

Gonadotropin-releasing hormone is a critical neurohormone involved in the regulation of reproduction in vertebrates and has extensively been studied in this clade. However, the time that $\mathrm{GnRH}$ signaling was considered to be unique to chordates has undoubtedly passed. At the moment, GnRH-like peptide sequences have been found in a wide variety of deuterostomian and protostomian phyla including indications of $\mathrm{GnRH}$-like material in the cnidarian lineage (Anctil, 2000; Twan et al., 2006). However, based on their primary functions in different phyla, consistency in the nomenclature of this peptide superfamily has been lost. It is clear that a comparative and phylogenetic approach, also thoroughly reviewed in (Roch et al., 2011) opens the view that the GnRH superfamily is composed of the ecdysozoan AKHs, lophotrozoan GnRHs, and (proto) chordate GnRHs. They all originate from a common ancestor that may represent one of the most ancient hormones to persist through metazoan evolution.

\section{ACKNOWLEDGMENTS}

The authors acknowledge the Research Foundation Flanders (FWO-Vlaanderen, Belgium G0767.09) and the Institute for Promotion of Innovation through Science and Technology in Flanders (IWT-Vlaanderen, Belgium) for financial support. The authors benefits grants from the FWO (KAN 1.5.093.10) and from the Research Foundation of the K.U. Leuven (GOA/2010).

\section{REFERENCES}

Abdel-Latief, M., and Hoffmann, K. H. (2007). The adipokinetic hormones in the fall armyworm, Spodoptera frugiperda: cDNA cloning, quantitative real time RT-PCR analysis, and gene specific localization. Insect Biochem. Mol. Biol. 37, 999-1014.

Adams, B. A., Tello, J. A., Erchegyi, J., Warby, C., Hong, D. J., Akinsanya, K. O., Mackie, G. O., Vale, W., Rivier, J. E., and Sherwood, N. M. (2003). Six novel gonadotropinreleasing hormones are encoded as triplets on each of two genes in the protochordate, Ciona intestinalis. Endocrinology 144, 1907-1919.

Anctil, M. (2000). Evidence for gonadotropin-releasing hormonelike peptides in a cnidarian nervous system. Gen. Comp. Endocrinol. 119, 317-328.

Di Cristo, C., De Lisa, E., and Di Cosmo, A. (2008a). Control of $\mathrm{GnRH}$ expression in the olfactory lobe of Octopus vulgaris. Peptides 30, 538-544.

Di Cristo, C., De Lisa, E., and Di Cosmo, A. (2008b). GnRH in the brain and ovary of Sepia officinalis. Peptides 30, 531-537.

Gade, G. (2004). Regulation of intermediary metabolism and water balance of insects by neuropeptides. Annu. Rev. Entomol. 49, 93-113.

Gorbman, A., and Sower, S. A. (2003). Evolution of the role of GnRH in animal (metazoan) biology. Gen. Comp. Endocrinol. 134, 207-213.

Guilgur, L. G., Moncaut, N. P., Canario, A. V., and Somoza, G. M. (2006). Evolution of GnRH ligands and receptors in gnathostomata. Comp. Biochem. Physiol. A Mol. Integr. Physiol. 144, 272-283.

Hansen, K. K., Stafflinger, E., Schneider, M., Hauser, F., Cazzamali, G., Williamson, M., Kollmann, M.,
Schachtner, J., and Grimmelikhuijzen, C. J. (2010). Discovery of a novel insect neuropeptide/GPCR signaling system closely related to the insect adipokinetic hormone and corazonin hormonal systems. J. Biol. Chem. 285, 10736-10747.

Hua, Y., Ishibashi, J., Saito, H., Tawfik, A. I., Sakakibara, M., Tanaka, Y., Derua, R., Waelkens, E., Baggerman, G., De, L. A., Schoofs, L., and Tanaka, S. (2000). Identification of $\operatorname{Arg}(7)$ corazonin in the silkworm Bombyx mori and the cricket, Gryllus bimaculatus, as a factor inducing dark color in an albino strain of the locust, Locusta migratoria. J. Insect Physiol. $46,853-860$

Iwakoshi, E., Takuwa-Kuroda, K., Fujisawa, Y., Hisada, M., Ukena, K., Tsutsui, K., and Minakata, H. (2002). Isolation and characterization of a GnRH-like peptide from Octopus vulgaris. Biochem. Biophys. Res. Commun. 291, 1187-1193.

Janssen, T., Lindemans, M., Meelkop, E., Temmerman, L., and Schoofs, L. (2010). Coevolution of neuropeptidergic signaling systems: from worm to man. Ann. N. Y. Acad. Sci. 1200, 1-14.

Kah, O., Lethimonier, C., Somoza, G., Guilgur, L. G., Vaillant, C., and Lareyre, J. J. (2007). GnRH and GnRH receptors in metazoa: a historical, comparative, and evolutive perspective. Gen. Comp. Endocrinol. 153, 346-364.

Kanda, A., Takahashi, T., Satake, H., and Minakata, H. (2006). Molecular and functional characterization of a novel gonadotropin-releasinghormone receptor isolated from the common octopus (Octopus vulgaris). Biochem. J. 395, 125-135.

Kaufmann, C., and Brown, M. R. (2006). Adipokinetic hormones in the African malaria mosquito,
Anopheles gambiae: identification and expression of genes for two peptides and a putative receptor. Insect Biochem. Mol. Biol. 36, 466-481.

Kaufmann, C., and Brown, M. R. (2008). Regulation of carbohydrate metabolism and flight performance by a hypertrehalosaemic hormone in the mosquito Anopheles gambiae. J. Insect Physiol. 54, 367-377.

Kavanaugh, S. I., Nozaki, M., and Sower, S. A. (2008). Origins of gonadotropin-releasing hormone $(\mathrm{GnRH})$ in vertebrates: identification of a novel GnRH in a basal vertebrate, the sea lamprey. Endocrinology 149, 3860-3869.

Kim, D. K., Cho, E. B., Moon, M J., Park, S., Hwang, J. I., Kah, O. Sower, S. A., Vaudry, H., and Seong, J. Y. (2011). Revisiting the evolution of gonadotropin-releasing hormones and their receptors in vertebrates: secrets hidden in genomes. Gen. Comp. Endocrinol. 170, 68-78.

Kollisch, G. V., Lorenz, M. W., Kellner, R., Verhaert, P. D., and Hoffmann, K. H. (2000). Structure elucidation and biological activity of an unusual adipokinetic hormone from corpora cardiaca of the butterfly, Vanessa cardui. Eur. J. Biochem. 267, 5502-5508.

Li, B., Predel, R., Neupert, S., Hauser, F., Tanaka, Y., Cazzamali, G., Williamson, M., Arakane, Y., Verleyen, P., Schoofs, L., Schachtner, J., Grimmelikhuijzen, C. J., and Park, Y. (2008). Genomics, transcriptomics, and peptidomics of neuropeptides and protein hormones in the red flour beetle Tribolium castaneum. Genome Res. $18,113-122$.

Lindemans, M., Liu, F., Janssen, T., Husson, S. J., Mertens, I., Gäde, G., and Schoofs, L. (2009). Adipokinetic hormone signaling through the gonadotropin-releasing hormone receptor modulates egglaying in Caenorhabditis elegans. Proc. Natl. Acad. Sci. U.S.A. 106, 1642-1647.

Millar, R. P. (2005). GnRHs and GnRH receptors. Anim. Reprod. Sci. 88 5-28.

Morgan, K., and Millar, R. P. (2004). Evolution of GnRH ligand precursors and GnRH receptors in protochordate and vertebrate species. Gen. Comp. Endocrinol. 139, 191-197.

O'Shea, M., and Rayne, R. C. (1992). Adipokinetic hormones: cell and molecular biology. Experientia 48, 430-438.

Roch, G. J., Busby, E. R., and Sherwood, N. M. (2011). Evolution of GnRH: diving deeper. Gen. Comp. Endocrinol. 171, 1-16.

Rodet, F., Lelong, C., Dubos, M. P., Costil, K., and Favrel, P. (2005). Molecular cloning of a molluscan gonadotropin-releasing hormone receptor orthologue specifically expressed in the gonad. Biochim. Biophys. Acta 1730, 187-195.

Siegert, K. J. (1999). Locust corpora cardiaca contain an inactive adipokinetic hormone. FEBS Lett. 447, 237-240.

Staubli, F., Jorgensen, T. J., Cazzamali, G., Williamson, M., Lenz, C., Sondergaard, L., Roepstorff, P., and Grimmelikhuijzen, C. J. (2002). Molecular identification of the insect adipokinetic hormone receptors. Proc. Natl. Acad. Sci. U.S.A. 99, 3446-3451.

Stewart, A. J., Katz, A. A., Millar, R. P., and Morgan, K. (2009). Retention and silencing of prepro-GnRH-II and type II GnRH receptor genes in mammals. Neuroendocrinology 90 , 416-432. 
Tanaka, Y., Hua, Y., Roller, L., and Tanaka, S. (2002). Corazonin reduces the spinning rate in the silkworm, Bombyx mori. J. Insect Physiol. 48, 707-714.

Tello, J. A., and Sherwood, N. M. (2009). Amphioxus: beginning of vertebrate and end of invertebrate type GnRH receptor lineage. Endocrinology 150, 2847-2856.

Tostivint, H. (2011). Evolution of the gonadotropin-releasing hormone $(\mathrm{GnRH})$ gene family in relation to vertebrate tetraploidizations. Gen. Comp. Endocrinol. 170, 575-581.

Tsai, P. S., and Zhang, L. (2008). The emergence and loss of gonadotropin-releasing hormone in protostomes: orthology, phylogeny, structure, and function. Biol. Reprod. 79, 798-805.
Twan, W. H., Hwang, J. S., Lee, Y. H., Jeng, S. R., Yueh, W. S., Tung, Y. H., Wu, H. F., Dufour, S., and Chang, C. F. (2006). The presence and ancestral role of gonadotropin-releasing hormone in the reproduction of scleractinian coral, Euphyllia ancora. Endocrinology 147, 397-406.

Vadakkadath, M. S., Gallego, M. J., Haasl, R. J., Petras, S. J. III, Sgro, J. Y., and Atwood, C. S. (2006). Identification of a gonadotropin-releasing hormone receptor orthologue in Caenorhabditis elegans. BMC Evol. Biol. 6, 103. doi: 10.1186/1471-21486-103

Veenstra, J. A. (1989). Isolation and structure of corazonin, a cardioactive peptide from the American cockroach. FEBS Lett. 250, 231-234.
Zhang, L., Wayne, N. L., Sherwood, N. M., Postigo, H. R., and Tsai, P. S. (2000). Biological and immunological characterization of multiple $\mathrm{GnRH}$ in an opisthobranch mollusk, Aplysia californica. Gen. Comp. Endocrinol. 118, 77-89.

Zhu, C., Huang, H., Hua, R., Li, G., Yang, D., Luo, J., Zhang, C., Shi, L., Benovic, J. L., and Zhou, N. (2009). Molecular and functional characterization of adipokinetic hormone receptor and its peptide ligands in Bombyx mori. FEBS Lett. 583, 1463-1468.

Conflict of Interest Statement: The authors declare that the research was conducted in the absence of any commercial or financial relationships that could be construed as a potential conflict of interest.
Received: 18 March 2011; accepted: 16 June 2011; published online: 12 July 2011. Citation: Lindemans M, Janssen T, Beets I, Temmerman L, Meelkop E and Schoofs $L$ (2011) Gonadotropin-releasing hormone and adipokinetic hormone signaling systems share a common evolutionary origin. Front. Endocrin. 2:16. doi: 10.3389/fendo.2011.00016

This article was submitted to Frontiers in Neuroendocrine Science, a specialty of Frontiers in Endocrinology.

Copyright (c) 2011 Lindemans, Janssen, Beets, Temmerman, Meelkop and Schoofs. This is an open-access article subject to a non-exclusive license between the authors and Frontiers Media SA, which permits use, distribution and reproduction in other forums, provided the original authors and source are credited and other Frontiers conditions are complied with. 